\title{
Galvanic Corrosion of Brass /steel 907A Couple in Artificial Seawater
}

\author{
Li Jiang ${ }^{1,2, *}$, Qingsong Yang ${ }^{3}$, Xiaoqing $\mathrm{Du}^{1}$, Zhen $\mathrm{Xu}^{1}$, Yu Chen ${ }^{1}$, Zhao Zhang ${ }^{1}$, \\ Jianqing Zhang ${ }^{1}$,Chunan Cao ${ }^{1}$ \\ ${ }^{1}$ Department of Chemistry, Zhejiang University, Hangzhou 310027, China; \\ ${ }^{2}$ College of Materials Science and Engineering, China Jiliang University, Hangzhou 310018, China; \\ ${ }^{3}$ Zhanjiang Corrosion and Protection Center, Zhanjiang 524000, China \\ *E-mail: jiangliwhu@126.com
}

doi: $10.20964 / 110437$

Received: 4 February 2016 / Accepted: 3 March 2016 / Published: 1 April 2016

Galvanic corrosion of brass /steel 907A couples with various cathode /anode area ratios were examined by electrochemical impedance spectroscopy and electrochemical noise technique. Experimental results show that the galvanic corrosion of couples accelerate within the initial $24 \mathrm{~h}$, and then decrease in the later time (from $26 \mathrm{~h}$ to $720 \mathrm{~h}$ ). The products nucleation, growth, film formation stages are characterized using energy distribution plots (EDP) and two parameters $\left(n_{1}\right.$ and $\left.n_{2}\right)$ are adopted to differentiate the nucleation and growth processes. According to the variation tendency of $n_{l}$ and $n_{2}$, galvanic corrosion process are divided into fluctuating stage and stabilization stage. As the cathode /anode area ratios increase, the corrosion rates of brass /steel 907A couples increase and the period of fluctuating stage lengthens.

Keywords: Galvanic corrosion; Electrochemical noise technique; Brass; Steel 907A

\section{FULL TEXT}

(C) 2016 The Authors. Published by ESG (www.electrochemsci.org). This article is an open access article distributed under the terms and conditions of the Creative Commons Attribution license (http://creativecommons.org/licenses/by/4.0/). 